\title{
International Journal of Applied Science and Engineering Review
}

IJASER

ISSN: 2582-6271

Vol. 2, Issue.6, Nov-Dec 2021, page no. 39-44

To cite this article: Jian Xiang (2021). COMPANY INFORMATION MANAGEMENT SYSTEM DESIGN AND RESEARCH, International Journal of Applied Science and Engineering Review (IJASER) 2 (6): 39-44

\section{COMPANY INFORMATION MANAGEMENT SYSTEM DESIGN AND RESEARCH}

\author{
Jian Xiang \\ School of Information and Electronic Engineering, \\ Zhejiang University of Science and Technology, HangZhou, 310023, China
}

DOI: http://dx.doi.org/10.52267/IJASER.2021.2604

\begin{abstract}
The content of this graduation design is to design and implement a web-based enterprise information management system, the system is mainly based on j2EE development, mainly using a combination of struts2+spring+hibernate and other frameworks, using MyEclipse as a development tool, MYSQL as the database, DCloud's HBuilder as the interface beautification tools, using JAVA language development, the page to take JSP dynamic page development technology. The system interface is simple, easy to operate and easy to maintain.
\end{abstract}

KEYWORDS: Enterprise Information Management System, JSP, JAVA

\section{INTRODUCTION}

With the rapid development of various modern information technologies, which has pushed society to stride from the industrial age to the information age, people pay more and more attention to the optimization role played by information technology in traditional industries, and the level of information management and utilization of information resources has become an important component of the strength to measure the comprehensive strength of a company. The enhancement of information technology has made knowledge and information an important strategic resource for the national economy. The development of information technology, especially the microcomputer revolution and digital revolution makes information resources computerized, and turns the disordered information into orderly and valuable information, people can use various ways and tools to process the information, retrieve and utilize it in any way and tool according to the user's requirements, and can get any information they need at any place and any time, truly in the sense of turning information into resources. Since the 1990s, the Internet has been rapidly spreading around the world. People soon realized that this new information technology would have a significant impact on people's daily life and learning. At the same time, the reliability and security of network information became a 


\section{International Journal of Applied Science and Engineering Review}

IJASER

ISSN: 2582-6271

Vol. 2, Issue.6, Nov-Dec 2021, page no. 39-44

major concern. Therefore, it is an urgent issue to develop a secure, stable and reliable information management system with practical applications.

Current status: Regarding the overall application of enterprise information management system in China, the application in large enterprises and medium-sized enterprises is better than that in small enterprises, and the information management system of large enterprises has realized the transformation of integrated information management system, while the information management system of medium-sized enterprises has partially realized the transformation of integrated information management system, but due to the shortage of funds, weak information infrastructure, management However, the application of information management system in small and mediumsized enterprises is not good due to the shortage of capital, weak information infrastructure, management's indifference to information management system, and other factors such as avoidance of business risks. The size of the enterprise also limits the development of information technology degree of small and medium-sized enterprises, the degree of information technology construction of small and medium-sized enterprises will be constrained due to lack of funds, management irregularities and other reasons. Small and medium-sized enterprises on the way to information technology construction is the biggest obstacle is low profits, lack of funds. At the same time, due to financial constraints and thus can only choose relatively inexpensive, general-purpose information management software, while the software itself due to the defects of the more complex business generation management and business processing methods there is an obvious lack of functionality.

\section{SIGNIFICANCE OF THE STUDY}

A good enterprise information management system can reduce the workload of staff, provide the quality of products to improve the image of the company, as a business, it is vital to deliver the company's information to the relevant customers in a timely and error-free manner. Therefore, the information management of the enterprise is more important to ensure the authenticity, advancement and regularity of the information. From the development direction of technology, our enterprise information management system should realize digital office. The so-called digital office is to say that nearly all office operations are realized in the network environment. The essence of the digital office construction is to improve the effectiveness of decision-making, and through the realization of office automation to optimize the current organizational structure of enterprise management, adjust the management system, and on the basis of improving efficiency, increase the ability to work together, strengthen the consistency of decision-making, and finally achieve the purpose of improving the effectiveness of decision-making. Therefore, the full realization of digital office is the inevitable trend of the development of enterprise information management system. 


\section{International Journal of Applied Science and Engineering Review}

IJASER

ISSN: 2582-6271

Vol. 2, Issue.6, Nov-Dec 2021, page no. 39-44

With the development of information and communication technologies, as well as the application of computers and networks in modern management. Only resume efficient and practical information management system, the enterprise can cope with more and more information resources and more and more complex internal and external environment of the enterprise, and provide guarantee for analysis and decision making and control, so as to realize the modernization of management. Information is a very important social resource, and only by mastering information resources can we make better use of various tangible resources and bring them into better and better effect. Information management is the basis and means of enterprise decision analysis, and through the understanding of various internal and external objective situation in order to make correct and better analysis and decision-making, the exact information is the basis of enterprise decision-making, and to promote the improvement of enterprise management. Information management is an important basis for the implementation of management control, the use of information to control the entire production process, the operation of the service process, is an important initiative to improve the quality of management, and to bring convenience to modern management.

\subsection{Business Requirements Overview}

Through the company's experience in the use of OA systems and daily work and for the network of relevant information, found that there are basically the following basic requirements.

Users: Process management and business processing using enterprise information management system can be divided into three types, administrators, supervisors and employees.

Administrator: Send messages to all employees and supervisors, add, delete and check functions for departments, employees, awards and penalties, training, further training, payroll, customers and commodities, assign privileges to employees, and assign supervisors to departments.

Supervisor: view messages sent by administrator, change login password, view your personal information, view employee attendance information, weekly, monthly and work logs, fill in weekly, monthly and work logs, agree to leave and overtime applications for employees in your department, check training, further training, salary, customer and product information.

Employees: View messages sent by administrators, change login password, view their personal information, their attendance information, fill in weekly reports, monthly reports and work logs, submit leave and overtime applications, check training, further training and payroll information.

\subsection{System Business Description}




\section{International Journal of Applied Science and Engineering Review}

IJASER

ISSN: 2582-6271

Vol. 2, Issue.6, Nov-Dec 2021, page no. 39-44

Information management function is mainly used to send out information to all employees, department management function is used to add, delete and check departments and their related attributes, employee management function is used to add, delete and check employees, reward and punishment records are used to reward and punish related employees, training records are used to give employees training news, payroll management is used to manage employees' salaries. Information query can view the information sent by the administrator, work plan management for the supervisor is to fill in their own work plan and view the work plan of their own department employees two functions, for employees only fill in their own work plan function. Work log management has two functions for supervisors to fill in their own work logs and view the work logs of employees in their own departments, and only fill in their own work logs for employees. Attendance management has two functions for supervisors to view their own attendance and that of their department employees, and only one function for employees to view their own attendance. The personal training record inquiry is to check the training information given by the administrator; the further training inquiry is to check the further training information given by the administrator; the salary management has the function of checking the salary of oneself and the employees in the department for the department supervisor, and only the function of checking one's own salary for the employees.

\subsection{System Implementation}

In this enterprise information management system design and development process I encountered many problems, such as the link between the staff module and the department module, because it is the first time to do the design and development of the relevant website. For the requirements of the relationship and the link between the modules is not very well understood, especially in the establishment of data tables, the relationship between the tables once made me quite a headache, later in the company through the current employment OA system after the study. I have a little hazy understanding of enterprise information management system, but not enough to complete the design of the entire system. Therefore, I logged on to Github and downloaded some project code related to my system and their database design tips and principles from it, and after referring to their code I had a certain degree of confidence in the enterprise information management system. It's still a slightly simple database design, but it's enough to support the current not-so-complex project.

After the database design, in the process of interface design, I have also encountered part of the frontend design problems, but because of the reference company OA system, most of the problems encountered in the colleagues have been answered and explained, so here not to do too much to explain. 


\section{International Journal of Applied Science and Engineering Review}

IJASER

ISSN: 2582-6271

Vol. 2, Issue.6, Nov-Dec 2021, page no. 39-44

For this project to use the framework, hit the beginning of the framework I intend to use is actually want to use the current hot spring boot, but for this framework is not very familiar with the more familiar now can only use the ssh framework.

The solution in this system has achieved the desired goal in this design. The deficiencies of this system are.

The user rights module is not designed enough, only 3 levels exist first. But in the actual real life there should be more different user levels. Or we can use role system to implement user permission level system.

Functionality implementation is relatively basic and communal, and there are no more specialized and advanced features that should be changed significantly when applied to real companies.

In real life enterprise information management system should have a large number of other devices to achieve a variety of operations such as punch cards.

For the first deficiency, in fact, the initial construction of the role system has been initially realized in this system, because it is unfamiliar with the work of other positions, so it is impossible to add more roles to enrich the role system. At the same time, there are also reasons for the project development cycle. There is still a lack of time to add more roles for improvement. As for the second deficiency, because there is no realistic and complete enterprise information management system with a considerable user base for reference, only simple and basic processes can be added. The third deficiency is not really a deficiency, which itself is the project deployment to the site is the need to improve the content of this and other systems, other equipment interface content needs to be provided in the case of other systems interface to improve the deficiency.

For the enterprise information management system still has some praiseworthy advantages, such as the foundation of the role of the system, has built a good foundation of the skyscraper will be easier to build down. The second is that for the enterprise internship so far there has been an understanding of the staff to use more features have been solved and improved the function, and will do more things in the usual work but not in the company's OA system features have been added to the project, such as weekly and monthly reporting functions. The third is about the front-end design of the interface, although it is a reference to the $\mathrm{H}+$ front-end framework, but the front-end interface design is quite pleasing to the eye, the operation is also very convenient. And in the login interface, you can distinguish the account authority level to enter different operation main interface. 


\section{International Journal of Applied Science and Engineering Review}

IJASER

ISSN: 2582-6271

Vol. 2, Issue.6, Nov-Dec 2021, page no. 39-44

\section{CONCLUSION}

Through this project design, I have some feelings about SSH framework and front-end design. It is still full of accomplishment when watching an interface become a little bit beautiful under my own hands, and a function is gradually improved under my own hands. Although there are many features and interface designs in my mind that I cannot realize because of my technical level, so I have to give up these ideas. However, I have recorded the ideas that came to my mind during the implementation process in my computer, and these ideas will be implemented with changes in my future projects. These ideas will be a boost to my career.

\section{References}

[1] Bruce Eckel. Java Programming Ideas (Fourth Edition) [M]. Beijing: Machinery Industry Press,2007

[2] Zheng Aqi, Yu Yan. Java EE Project Development Tutorial (2 ed.) [M]. Beijing: Electronic Industry Press, 2013

[3] David Flanagan. JavaScript: The Definitive Guide [M].US: O'Reilly Media, Inc. 2011

[4] Meng, Xiangrui. Management Information System [M]. Shanghai: East China University of Science and Technology, 2005

[5] Sun Weiqin. Proficient Hibernate: Java Object Persistence Technology Explained [M], Beijing: Electronic Industry Press, 2005

[6] Liu J, Shen RF. Enterprise information management system: concepts, development, problems and research directions: Journal of Systems Engineering

\section{Author Profile}

Taro Denshi received the B.S. and M.S. degrees in Environment Engineering from Shibaura Institute of Technology in 1997 and 1999, respectively. During 1997-1999, he stayed in Communications Research Laboratory (CRL), Ministry of Posts and Telecommunications of Japan to study digital beam forming antennas, mobile satellite communication systems, and wireless access network using stratospheric platforms. He now with DDI Tokyo Pocket Telephone, Inc. 